\title{
Water-Soluble Vitamin
}

National Cancer Institute

\section{Source}

National Cancer Institute. Water-Soluble Vitamin. NCI Thesaurus. Code C1551.

Vitamins that are freely soluble in water. 